\title{
Epistemología de la techne: a propósito del fraude informático
}

\author{
Epistemology of techne: apropos of informatics fraud
}

FERNANDO MUÑOZ LEÓN

Facultad de Ciencias Jurídicas y Sociales, Universidad Austral de Chile

\begin{abstract}
RESUMEN ¿Son las máquinas distintas de los hombres? Así lo sostiene la dogmática nacional en materia de fraude informático, planteando la necesidad de que el legislador tipifique dicho ilícito. En un afán de problematizar los presupuestos epistemológicos que subyacen a dicha tesis dogmática, este trabajo relativiza el dualismo ontológico que distingue entre hombre y máquina a través de una exploración filosófica del engaño.
\end{abstract}

PALABRAS CLAVE Filosofía de la tecnología, epistemología del engaño, dualismo hombre/máquina.

ABSTRACT Are machines different from men? Our legal doctrine on informatics fraud so declares, when summoning the legislator to criminalize this evil. With the purpose of problematizing the epistemological assumptions that sustain this doctrinal thesis, this work relativizes the ontological dualism that distinguishes men from machines through a philosophical exploration of deceit.

KEYWORDS Philosophy of technology, epistemology of deceit, man/machine dualism. 
Pero, puesto que todas las facultades del alma dependen de la adecuada organización del cerebro y del cuerpo en general, a tal punto que no son evidentemente otra cosa sino esta organización misma, he abí una máquina bien iluminada. Pues, al fin, aun cuando sólo el hombre hubiera recibido en herencia la ley natural, ¿sería menos, por eso, una máquina? Julien Offray de La Mettrie, El hombre máquina (I748)

Me interesa indagar en los presupuestos que subyacen a una tesis que, en el plano de la dogmática jurídica hoy en día prevaleciente en materia penal, no resulta controversial, pero cuyas implicancias epistemológicas e incluso ontológicas, según creo, son discutibles. Hago este ejercicio confiado en que el público lector de la Revista Chilena de Derecho y Tecnología tiene un interés en la tecnología que excede de lo inmediatamente práctico; es decir, que se aproxima a aquello que, con propiedad, es calificado como amor por el saber, filosofía. De todas maneras, como Tales de Mileto, confío en que dicho saber, tarde o temprano, podrá serle de utilidad a quienes lo posean. En el intertanto, léase este trabajo como un ejercicio por escarbar en los fundamentos profundos de nuestras creencias jurídico-dogmáticas.

\section{EPISTEMOLOGÍA DEL ENGAÑO}

Demos un vistazo a la situación actual en materia de fraude informático. La obra todavía canónica en esta materia es la contenida en el libro Delincuencia y fraude informático, de Claudio Magliona y Macarena López, publicado en I999. La vigencia dogmática de esta obra se debe, en no menor medida, al hecho de que desde entonces nuestra legislación en la materia no ha cambiado, asunto al cual le dedicaremos también algunas líneas.

La tesis que me interesa discutir sostiene que el delito de fraude contemplado en el Código Penal es inadecuado, en virtud del principio de tipicidad, para castigar el fraude informático. Por ello, sostiene la tesis, se hace necesario reformar de manera explícita nuestros textos legales 
para consagrar un nuevo instituto, el fraude informático. ${ }^{1}$ Para dar razón de la necesidad de este planteamiento de lege ferenda, Magliona y López explicitan el argumento ontológico que subyace a su diagnóstico: la «imposibilidad de engañar a una máquina», la "no existencia de un error psicológico por parte del computador que lo llevara a la disposición patrimonial lesiva» (I999: I83). Dada esta diferencia en el mundo extensional entre las personas y los computadores, en su constitución material, entonces es necesario dar un tratamiento distinto a ambos tipos de criminalidad, el fraude 'humano' y el fraude informático.

Ahora, ¿es cierto que no es posible engañar a una máquina? Valgámonos para intentar responder esta pregunta de la noción, hoy en día ampliamente difundida, de inteligencia artificial. Con este término, sin embargo, no quiero conjurar en la mente del lector ninguna fantasía asimoviana de robots dotados de supermentes autónomas. Quiero mantenerme por el momento alejado de la ciencia ficción, empleando una conceptualización más analítica de la inteligencia artificial. Por ejemplo, LaDuke ha señalado que la inteligencia es "conocimiento almacenado que puede ser recuperado en cualquier nivel social», y que, así entendida, la «inteligencia 'artificial' es conocimiento almacenado y recuperable artificialmente en cualquier nivel social» (2008: 72). Así formulado el concepto, ¿existe alguna diferencia entre la inteligencia artificial y la inteligencia natural o humana?

Ciertamente, una diferencia superficial radica en el soporte material de una u otra: la inteligencia artificial se localiza en mecanismos metálicos, mientras que la inteligencia humana es propia de una determinada criatura biológica, el ser humano. Una diferencia más profunda es que la inteligencia humana está en condiciones de alcanzar una autorrefencialidad de la que la inteligencia artificial, al menos actualmente, carece; una referencialidad de segundo orden, que le permite someter a revisión (al menos algunos) criterios epistémicos y conductuales. ${ }^{2}$ En otras pala-

I. Magliona y López conceptualizan a dicho ilícito como «la causación de un perjuicio económico irrogado mediante un comportamiento engañoso, astuto, o sea, un medio fraudulento, que en este caso sería la propia manipulación informática» (I999: I 89).

2. Esta caracterización de la autorreferencialidad epistémico-conductual, por cierto, ha sido siempre rechazada por quienes sostienen visiones deterministas del ser humano. El cuestionamiento más reciente viene del así llamado enfoque cognitivo, que estudia las 
bras, puede revisar y corregir (algunos de) sus criterios epistémicos para vincularse con su entorno y (algunas de) sus respuestas conductuales. ${ }^{3}$

$¿$ ¿Hay diferencias, entonces, entre el candado de un cofre, el lector de tarjetas de un cajero automático, un software de procesamiento de cuentas bancarias, y un contador sentado en la ventanilla de un banco? La respuesta inmediata de nuestra doctrina jurídica es que sí. Pero no porque haya una reflexión sobre las diferencias y similitudes entre el complejo epistémico-conductual de las máquinas y el complejo epistémico-conductual de los seres humanos. Más bien, pareciera haber un precompromiso con la respuesta positiva. Y ello porque nuestro orden moral, político y legal reposa sobre una visión librealbedrista del ser humano. Lo que pareciera ocurrir aquí es que, como han observado entre otros Taylor (2004) y Kahn (2005), el imaginario social moderno se construye en torno a una estructura de creencias sobre la libertad humana, de raigambre cristiana pero secularizada, en la cual se sustentan nuestras concepciones (liberales) de la representación política, de la libertad contractual y de la responsabilidad penal. Estos órdenes normativos nos resultan tan importantes que, comprensiblemente, no estamos dispuestos a arriesgar perturbar su estabilidad considerando la posibilidad de que no seamos tan distintos de las máquinas.

Quizás ése es el precompromiso que subyace a la afirmación rotunda de que no se puede engañar a una máquina; ello supone que la máquina no tiene autorreferencialidad de segundo orden, a diferencia nuestra. Pero no es necesario probar que los seres humanos carezcan de dicha autorreferencialidad, como podría querer un determinista, para disolver (o deconstruir) la diferencia entre máquinas y humanos. Para alcanzar dicho propósito basta con evidenciar que el engaño no involucra, no afecta, a la autorreferencialidad de segundo orden que diferenciaría al humano de la máquina, a la inteligencia natural de la inteligencia artificial.

predisposiciones no conscientes de los seres humanos que les llevan a adoptar ciertas actitudes ante temas tan diversos como la distribución adecuada de riesgos o la credibilidad de fuentes informativas. Para una reciente exploración de estos temas en el contexto del derecho, véase Kahan (20II).

3. LaDuke se refiere a esto, para distinguirlo de la inteligencia, como la creación de conocimiento. Por esto afirma que la inteligencia artificial ya existe, y que aquello a lo que la ciencia ficción nos tiene acostumbrados y que los investigadores intentan crear hoy en día es la creación artificial de conocimiento (2008: 72). 
Esto es, efectivamente, así. El engaño castigado por el delito de fraude en el derecho contemporáneo consiste en detectar patrones epistémicos de la víctima y distorsionar la representación que ella obtiene a través de ellos: así, por ejemplo, "usando de nombre fingido, atribuyéndose poder, influencia o crédito supuestos, aparentando bienes, crédito, comisión, empresa o negociación imaginarios, o valiéndose de cualquier otro engaño semejante», según el artículo 468 del Código Penal. Aquí no se actúa sobre la capacidad del humano de transformar reflexivamente —es decir, a mediano plazo, en una serie repetida de juegos— su aparato epistémico y sus respuestas conductuales.

Ahora bien, este engaño no es ontológicamente distinto de hacer «uso de llaves falsas, o de verdadera que se hubiere sustraído, de ganzúas u otros instrumentos semejantes», para emplear los términos del artículo 442 del Código Penal. Y así podríamos sostener que, ontológicamente, romper a martillazos un candado es distinto que abrirlo con una ganzúa, tal como abrir a hachazos un cajero automático lo es de emplear una banda magnética trucada, tal como acuchillar a alguien para robarle lo es de contarle el 'cuento del tío'. El bien jurídico central, en todos los casos, es la propiedad; pero los medios a través de los cuales se afecta dicho bien son disímiles en cada binomio. El martillo, el hacha, y el cuchillo son techne no inteligente, que a su vez no reconocen en sus víctimas ningún tipo de inteligencia, pues en sí mismas carecen de un aparato epistémico. La ganzúa, la tarjeta magnetizada, el 'cuento del tío', son techne que, utilizadas por un sujeto, les permiten reconocer ciertos patrones en el aparato epistémico de una cierta inteligencia, artificial en los primeros dos casos - el candado y el cajero automático- y natural en el tercero, y utilizar dichos patrones en beneficio del victimario. En cuanto estrategias delictivas, no difieren ontológicamente entre sí.

En conclusión, no es cierto que no podamos engañar a los computadores.

\section{ONTOLOGÍA DE LA TECHNE}

Esta conclusión está vinculada a otra tesis que es importante explicitar, y que respalda la unificación que en el anterior apartado he hecho entre hachas, cuchillos, ganzúas, candados y computadores, subsumiendo todos estos artefactos dentro de la categoría de techne. Mi idea al res- 
pecto es que la techne viene efectivamente a cambiar los parámetros de la experiencia humana; pero que su llegada, y este efecto revolucionario sobre lo humano, se produjeron hace ya mucho tiempo. Por lo tanto, no es extraño que formas de comprender la criminalidad informática que se sustenten en lo novedoso e inusitado de esta última estén dejando pasar importantes aspectos en los cuales las cosas no han cambiado tanto.

¿Qué quiero decir con esto? Me parece que la mejor forma de explicarlo consiste en hacer uso de la distinción que Hannah Arendt hace entre potencia, poder y violencia. "Poder», argumenta nuestra autora, «corresponde a la capacidad humana, no simplemente para actuar, sino para actuar concertadamente. El poder nunca es propiedad de un individuo; pertenece a un grupo y sigue existiendo mientras que el grupo se mantenga unido» (2005: 60). «Potencia», por su parte, "designa inequívocamente a algo en una entidad singular, individual; es la propiedad inherente a un objeto o persona y pertenece a su carácter, que puede demostrarse a sí mismo en relación con otras cosas o con otras personas, pero es esencialmente independiente de ello» (2005: 6I) «La violencia», en cambio, «fenomenológicamente está próxima a la potencia, dado que los instrumentos de la violencia, como todas las demás herramientas, son concebidos y empleados para multiplicar la potencia natural hasta que, en la última fase de su desarrollo, puedan sustituirla» (2005: 63). El siguiente aforismo resume la propuesta terminológica y conceptual de Arendt: «la extrema forma de poder es la de Todos contra Uno, la extrema forma de violencia es la de Uno contra Todos. Y esta última nunca es posible sin instrumentos» (2005: 57).

El paso de la potencia a la violencia, entonces, está dado por ciertos instrumentos que, como todas las demás herramientas, son concebidos y empleados para multiplicar las propiedades inherentes a un objeto o persona. A eso llamo aquí techne. Ahora, ¿cuándo ocurre este paso de la potencia a la violencia a través de la techne? ¿Con la aparición de las ametralladoras y las cámaras de gases? No, ocurre mucho antes, en el paleolítico, con la invención de las lanzas, las puntas de flecha y las hachas. La idea de que la techne ya lleva mucho tiempo revolucionando la experiencia humana debe ser aplicada también a aquella variedad de techne que he denominado como inteligencia artificial. Inteligencia artificial, como he señalado anteriormente, no puede equivaler a los robots pensantes y con emociones a los que la ciencia ficción nos tiene acostum- 
brados. En función del uso que he hecho anteriormente de este concepto, y buscando una definición de inteligencia artificial que sea general, no casuista ni menos ficticia (es decir, imposible), me parece que por tal concepto tendríamos que entender aquel sistema que interactúa con su entorno seleccionando información mediante un determinado aparato epistémico, y que frente a la información considerada por el mismo sistema como relevante reacciona entregando respuestas conductuales consistentes.

El entorno digital, no lo pongo en duda, cambia muchas cosas. Particularmente, acelera la multiplicación que de nuestras potencias ha realizado siempre la techne. Cuando Walter Benjamin hablaba de los efectos de la reproductibilidad tecnológica sobre el aura del arte, sobre su carácter único (místico), pensaba en la serigrafía y la imprenta, no en la piratería digital. Aun así, la estructura fundamental de la relación entre potencia y techne, de la cual la violencia es sólo una entre muchos posibles resultados, permanece básicamente inalterada. Ya hay techne, y techne inteligente, desde el remoto momento en que alguien crea un candado.

\section{TECNOLOGÍAS DE LA LEGISLACIÓN}

Ahora, si estamos confrontados a esta pregunta sobre la tipicidad del fraude informático es por la llamativa ineficiencia del legislador en esta materia. Y digo llamativa, pues la Ley I9.223, de figuras penales relativas a la informática, iniciada mediante la moción de un parlamentario (José Antonio Viera-Gallo), pareciera ser fruto de una era pretérita, en la que los parlamentarios legislaban y sus iniciativas podían aspirar a convertirse en ley.

Si esta era se ha acabado no es tanto debido a aquel acertado diagnóstico de Schmitt que explica el surgimiento de lo que él llama el legislador motorizado, esto es, a «la presión por adaptar la reglamentación legal a circunstancias rápidamente cambiantes» (2009a: 67). Tampoco se debe a su, también acertada, observación de que «la situación del parlamentarismo es hoy tan crítica porque la evolución de la democracia moderna de masas ha convertido la discusión pública que argumenta en una formalidad vacía» (I990: 9). Más bien, en el caso chileno, el fin de la eficacia legislativa del legislador pareciera haber fluido como conclusión de una 
distribución de competencias legislativas que lleva al extremo aquel otro planteamiento suyo según el cual el Jefe de Estado representa «un contrapeso al pluralismo de los grupos sociales y económicos del poder», y garantiza «la unidad del pueblo como conjunto político» (2009b: 286); ${ }^{4}$ propósito que, en el caso chileno, se ha traducido, como ha sido observado, en un sistema que neutraliza la agencia política del pueblo.

Una de las consecuencias de esta neutralización del proceso legislativo ha sido el fracaso, hasta el momento, en materia de reforma a nuestra legislación sobre delitos informáticos, asunto en el que hemos contemplado ya demasiadas falsas partidas. El proyecto de ley contenido en el Boletín 3009-07, originado en una moción parlamentaria, archivado desde el I9 de marzo de 2003; el proyecto de ley contenido en el Boletín 2974-I9, originado en una moción parlamentaria, modificatorio de la

4. Llegados a este punto, se vuelve necesario hacer un breve excurso que, lamentablemente, pareciera ser necesario realizar constantemente. ¿Qué necesidad hay de citar aquí a un autor de moralidad tan cuestionable como Schmitt? Esta pregunta se repite una y otra vez en foros y debates universitarios, de vez en cuando en columnas de opinión, y algo, aunque mucho menos, en publicaciones propiamente académicas. La respuesta, que en un contexto específicamente académico debiera ser obvia, es que la moralidad de un pensador es irrelevante a efectos de enjuiciar teórica o políticamente sus ideas. Su persona, desde luego, también puede ser objeto de juicio, pero eso es un asunto que debiera interesar a la historia política, en lugar de a la historia de las ideas. Ahora, el punto aquí con Schmitt es que él forma parte de una generación tremendamente prolífica en materia de reflexión sobre la tecnología: aquella alemana que vivió durante la república de Weimar y que vivió, desde muy distintas perspectivas, el dramático destino de este proyecto político. A esa generación pertenecieron Heidegger y el propio Schmitt, así como también Arendt, Benjamin, Horkheimer y Adorno. Estos autores, a mi juicio, pertenecen a una generación no sólo por el simple hecho de su coetaneidad y coterraneidad, sino más bien por la existencia de temáticas comunes: el riesgo de enajenación que implica la tecnología, su potencial para la violencia, la transposición de las lógicas de la tecnología hacia el campo cultural. Estas ideas están muy claramente, por ejemplo, en Heidegger y en Horkheimer/Adorno, pero también las encontrará un lector atento en Schmitt. Weimarianos de izquierda y de derecha, cabe observar, parecieran estar hermanados por un cierto pesimismo, al menos en su semblante, sobre lo que la tecnología representa para la humanidad. En ello son más herederos de William Blake que de Adam Smith. ¿Por qué se da esta particular coincidencia generacional? Vale la pena reflexionar en lo dicho por Dusek: «en Alemania, la derrota en la I Guerra Mundial condujo a una oleada popular de desencanto con la tecnología y a un interés neorromántico en el 'retorno a la naturaleza'»(2009: I32). 
Ley I 9.223, archivado y desarchivado durante su segundo trámite constitucional en 2007 y sin movimiento desde entonces; el proyecto de ley contenido en el Boletín 3083-07, originado en el mensaje presidencial I3-348, archivado en 2007, desarchivado en 2008, y sin movimiento desde entonces. A eso debemos sumarle dos proyectos de Código encargados por distintos gobiernos a distintos grupos de académicos: uno, por el de Ricardo Lagos, disponible para su consulta por la opinión pública, pero nunca enviado a tramitación; otro, por el de Sebastián Piñera, y que hasta el momento no ha sido dado a conocer. Cabe observar que, según se dice por variados comentaristas, uno de los problemas más grandes de esta ineficacia radica en la inexistencia de un tipo penal de fraude informático, el cual no fue incorporado en la Ley I9.233.

La ineficacia del legislador debe ser vista a la luz de la noción de violencia de Arendt. La ordenación del proceso legislativo contenida en nuestra Constitución es también una techne. Y ella multiplica la potencia de uno, el Presidente de la República, de tal manera que excede a la de muchos, los parlamentarios, y a través de ellos, y mediante la techne del veto legislativo, a la de todos, es decir, a la del pueblo. La preponderancia del Presidente en el proceso legislativo es una institucionalización de la violencia política.

La ineficacia del legislador, sin embargo, no es una mala noticia para la dogmática jurídica y sus disciplinas concurrentes. ${ }^{5}$ Esto ya lo sabía Savigny, y nos lo recordó Tarello. Ambos enfatizaron que, junto a la legislación, y en ocasiones en reemplazo de ella, la dogmática jurídica puede a menudo proporcionar soluciones a los problemas del presente, con los materiales jurídicos ya existentes, a través de sus construcciones intelectuales. ${ }^{6}$

5. Considerando el nivel de institucionalización de la academia en Chile, se vuelve imperioso evitar la peyorativa calificación de 'auxiliares' para referirse a las otras ciencias jurídicas, aquellas que estudian el fenómeno jurídico desde perspectivas externalistas, como las que estudian la causalidad sincrónica del derecho (historia del derecho), su causalidad diacrónica (sociología del derecho), la racionalidad instrumental que le subyace (análisis económico del derecho) y la estructura simbólico-cultural que le caracteriza (antropología del derecho).

6. La posibilidad de que este esfuerzo sea fructífero depende, por cierto, de la existencia de un orden político que estabilice la fuerza disruptiva del acto reinterpretativo. En ausencia de dicho orden, adviene el caos. Véase Novoa (I992). 
Ahora, la ciencia o, como preferimos llamarla nosotros, dogmática jurídica reposa sobre la base de ciertos presupuestos, entre los cuales se encuentra el que los desacuerdos relevantes para la materia en cuestión han sido previamente suprimidos o superados, asunto que ha llevado recientemente a Fernando Atria a caracterizar a la dogmática como una ciencia paleontológica, una ciencia del lenguaje muerto. Schmitt, nuevamente, sostuvo que «todos los conceptos, las expresiones y los términos políticos poseen un sentido polémico», sin el cual «devienen abstracciones vacías y fantasmagóricas» (2004: I 8I). El lenguaje del derecho es un lenguaje que ha perdido su carácter polémico, para hacer posible la creación de un espacio simbólico común entre nosotros, los ciudadanos: la fraternidad cívica, la cual nos lleva a disciplinar nuestros desacuerdos a través de la fuerza civilizadora del derecho.

Pero el problema del formalismo conceptualista del derecho es que, al no estar vivo, no es capaz de someter a discusión sus conceptos sino con el estrecho propósito de mantener su coherencia interna. Como señala Niklas Luhmann, «la labor del sistema tal como el propio sistema se lo representa consiste en distinguir los intereses protegidos por el derecho de los intereses que deben ser suprimidos y combatidos», distinción que «no puede ser derivada del entorno del sistema, ni puede ser 'vista' como una cualidad inherente de los sistemas. La distinción debe ser construida mediante operaciones internas» (I992: I430-I). La dogmática jurídica corre entonces el riesgo permanente de quedar entrampada con conceptos muertos protegiendo articulaciones muertas de intereses muertos.

¿Existe la posibilidad de que dogmáticamente el fraude 'humano' sea reconfigurado para inscribir dentro de él al fraude informático? La sola pregunta ya parecería peligrosa, cuestionable, discutible, a la luz de los presupuestos axiológicos de la dogmática penal. Una versión menos peligrosa a la luz de dichos presupuestos, entonces, plantearía que, la tipificación del fraude informático en sus propios términos se podría eventualmente beneficiar de las reflexiones epistémicas desarrolladas por la propia dogmática y por la jurisprudencia a lo largo de la historia de la aplicación de este tipo penal. Ambas alternativas debieran, desde luego, ser exploradas por los juristas correspondientes. Mal que mal, en ello consiste la función que les es socialmente confiada, no en el rechazo a la formulación de preguntas por su eventual peligrosidad. 


\section{CONCLUSIÓN: HACIA LA SUPERACIÓN DEL DUALISMO HOMBRE/MÁQUINA}

La epistemología que subyace a la dogmática prevaleciente sobre fraude informático se sustenta en un dualismo ontológico que considera al hombre y a la máquina como dos entes distintos entre sí. Ese dualismo ontológico tiene un innegable sustrato intuitivo; los hombres y las máquinas son, evidentemente, dos tipos de ser muy distintos. Ahora bien, el saber, tanto en su variante filosófica como científica, no puede satisfacerse con lo intuitivo. Debe ir más allá e interrogar, como decía Millas, hacia el límite.

Entonces, surge la pregunta: ¿en qué son distintos el hombre de la máquina? Quizás la respuesta a esta pregunta que resumiría de mejor manera la tradición filosófica occidental sería aquella que diría que la diferencia radica en el libre albedrío del que el primero goza y la segunda carece. Ahora bien, no es necesario recurrir a la filosofía kantiana para descartar que dicha respuesta provea un vistazo definitivo a la cosa en sí, a la esencia que diferencia al hombre de la máquina. Tampoco se trata de que aquí acometamos la tarea titánica de rebatir la tesis que califica al hombre como libre; ni siquiera de que sugiramos la posibilidad de que las máquinas, llegado el escatológico momento de la singularidad tecnológica, desarrollen dicho atributo, humanizándose. Basta con señalar que la construcción de categorías ontológicas, en una ontología no metafísica, es perspectivista: ellas se sustentan no en la totalidad o la esencialidad del ser, sino en la perspectiva que el observador adopte, perspectiva desde la cual describirá el mundo que observa y, eventualmente, su propio acto de observar. Por eso, en una ontología no metafísica, el ser mantiene la propiedad clásica de ser análogos; en parte iguales, en parte distintos. La ontología no metafísica reconoce la multiplicidad de perspectivas desde las cuales considerar al ser. Esto abre las puertas a la posibilidad de que reconozcamos que hombres y máquinas son, en parte, iguales, $y$, en parte, distintos. Por ejemplo, ambos comparten la cualidad, para nuestros efectos trivial, de existir en el mundo extensional, no ficticio. También tienen la cualidad, nuevamente trivial para nuestros efectos, de ser cada uno de los entes que integran cada categoría entes finitos, es decir, individuales, por lo cual cada hombre no es al mismo tiempo otro hombre, ni tampoco una máquina.

Reformulemos, entonces, la pregunta anterior de la siguiente mane- 
ra: ¿existe algún sentido no trivial en el cual hombres y máquinas sean iguales, o, incluso, lo mismo? Interesantemente, la producción conjunta de Maturana y Varela se inicia precisamente mediante un acto tal de monismo ontológico respecto de hombres, en cuanto seres vivos, $\mathrm{y}$ máquinas. Una máquina, observan Maturana y Varela, «es un sistema que puede materializarse mediante muchas estructuras diferentes y cuya organización definitoria no depende de las propiedades de los componentes» (2008: 66-7). Que máquinas y hombres estén constituidos de componentes metálicos y de tejidos biológicos, desde la perspectiva que ambos autores adoptan, es irrelevante. «El hecho de que los sistemas vivos son máquinas no puede demostrarse apelando a sus componentes» (2008: 66), señalan. «Más bien se debe mostrar su organización mecanicista de manera tal, que sea obvio cómo todas sus propiedades surgen de ella» (2008: 66). En el tratamiento de la cuestión que hacen Maturana y Varela, tanto seres vivos como máquinas de fabricación humana aparecen como máquinas; esto es, como unidades de producción. La diferencia entre unos y otros es, para Maturana y Varela, el resultado de su producción: mientras los seres vivos son máquinas homeostáticas que, produciéndose constantemente a sí mismas, mantienen constante su propia organización, las máquinas de fabricación humana son máquinas dinámicas que, pudiendo participar en la definición de la organización de otras máquinas, dependen en la definición de su propia organización de los procesos de producción de otras máquinas. Por eso, en su propuesta terminológica, Maturana y Varela describen a seres vivos como máquinas autopoiéticas y a las máquinas de fabricación humana como máquinas alopoiéticas.

Esta consideración de la ontología poiética —en sus términos, de la fenomenología mecanística- propuesta por Maturana y Varela es particularmente relevante para nuestra reflexión crítica sobre el dualismo hombre/máquina que caracteriza a la epistemología prevaleciente en materia de fraude informático. La propuesta teórica de estos destacados científicos, mal que mal, en sus orígenes se sustenta disciplinariamente en el estudio del sustrato biológico de ciertos procesos de cognición, particularmente de la visión. Ella, a su vez, tiene fuertes implicancias epistemológicas. Maturana y Varela reivindican a través de su teoría una cierta unidad de los procesos de observación - por lo tanto, de conocimiento- que no sólo nos hermana con los demás seres vivos, sino también 
con las máquinas. Si aceptamos sus proposiciones, quizás el ejercicio de asimilación realizado aquí entre hombres y máquinas debe ser radicalizado, llevado a sus correctas consecuencias éticas, que ciertamente no pueden ser las de reconocerle derechos fundamentales a las máquinas sino que volver a discutir los presupuestos epistemológicos de nuestro tratamiento de lo humano. Quizás Kraftwerk no sólo nos ofreció una versión del futurismo aggiornada a los estertores de la Guerra Fría; quizás nos ofreció también un programa filosófico, el punto de partida de un giro ontológico. Wir sind die Roboter. ${ }^{7}$

\section{REFERENCIAS}

Arendt, Hannah (2005). Sobre la violencia. Madrid: Alianza.

De la MetTrie, Julien Offray (1962). El hombre máquina. Buenos Aires: Eudeba.

Dusek, Val (2009). «Introduction: Philosophy and technology». A companion to the philosophy of technology (pp. I $3 \mathrm{I}-\mathrm{I} 4 \mathrm{O})$. Chichester: Blackwell.

KaHAN, Dan (20I I). "Neutral principles, motivated cognition, and some problems for constitutional law». Harvard Law Review, I 25: 2-77. Kahn, Paul (2005). Putting liberalism in its place. Princeton: Princeton University Press.

LADUKE, Bruce (2008). «Knowledge creation in collective intelligence». En Mark Tovey (editor), Collective intelligence: Creating a prosperous world at peace (pp. 65-74). Virginia: Earth Intelligence Network. LuHmann, Niklas (I992). «Operational closure and structural coupling: the differentiation of the legal system». Cardozo Law Review, I3: I4I9-I44I.

Magliona, Claudio y Macarena López (1999). Delincuencia y fraude informático: derecho comparado y Ley I9.223. Santiago: Jurídica.

7. El lector filosóficamente entrenado verá aquí un llamado a descartar el dualismo cartesiano mente/cuerpo, formulación cuyo atractivo para quienes suscriben una cosmovisión de inspiración cristiana es evidente pero que, en ausencia del precompromiso con la existencia del alma que tal cosmovisión implica, se revela como implausible. Qué queda una vez abolido dicho dualismo, de momento, es para el autor de este trabajo una pregunta todavía por explorar. 
Maturana, Humberto y Francisco Varela (2008). De máquinas y seres vivos. Autopoiesis: la organización de lo vivo. Santiago: Universitaria.

NovoA, Eduardo (1992). Los resquicios legales: un ejercicio de lógica jurídica. Santiago: Ediciones Bat.

Sснмітт, Carl (г990). Sobre el parlamentarismo. Madrid: Tecnos.

-. (2004). «El concepto de lo político». Carl Schmitt, teólogo de la política. Ciudad de México: Fondo de Cultura Económica.

-. (2009a). "The Motorized Legislator». High-speed society: social acceleration, power, and modernity. University Park: The Pennsylvania State University Press.

-. (2009b). El defensor de la Constitución. Madrid: Tecnos.

TAYlor, Charles (2004). Modern social imaginaries. Durnham: Duke University Press.

\section{SOBRE EL AUTOR}

Fernando Muñoz León es abogado por la Pontificia Universidad Católica de Chile, máster y doctor en Derecho por la Universidad de Yale, y profesor auxiliar en la Facultad de Ciencias Jurídicas y Sociales de la Universidad Austral de Chile. Su correo electrónico es <fernando.munoz@uach.cl>. El presente texto se origina en una ponencia presentada en el Seminario sobre Delitos Informáticos llevado a cabo el 5 y 6 de noviembre de 2013 en la Universidad de Chile, y organizado por el Centro de Estudios en Derecho Informático de dicha casa de estudios en conjunto con la ONG Derechos Digitales, llevado a efecto con el apoyo del Programa Cyber Stewards del Citizen Lab de la Universidad de Toronto. El autor agradece cordialmente a ambas organizaciones, especialmente a Claudio Ruiz, Alberto Cerda, Francisco Vera y Daniel Álvarez, así como también a Salvador Millaleo por los comentarios que formulara a esta ponencia durante el seminario.

Este trabajo fue recibido el 3 de diciembre de 2013 y aprobado el 9 de enero de 2014 . 